\title{
Danger above: a classic case of an unruptured right sinus of Valsalva aneurysm
}

\author{
Hayan Jouni, ${ }^{1}$ Steven L Driver, ${ }^{1}$ R Scott Wright, ${ }^{2}$ Farris Timimi ${ }^{2}$ \\ ${ }^{1}$ Department of Internal Medicine, Mayo Clinic, Rochester, Minnesota, USA \\ ${ }^{2}$ Division of Cardiovascular Diseases, Department of Internal Medicine, Mayo Clinic, Rochester, Minnesota, USA
}

Correspondence to Hayan Jouni, Mayo Clinic, 200 First Street SW, Rochester, MN 55905; Jouni.Hayan@mayo.edu

HJ and SLD contributed equally to this paper

\section{DESCRIPTION}

A 78-year-old man with a medical history significant for hypertension, dyslipidaemia and obstructive sleep apnoea presented for evaluation of atypical chest pain and slowly progressive exertional dyspnoea. Cardiac auscultation revealed a diastolic murmur. Transthoracic echocardiography showed a right saccular aneurysm of the sinus of Valsalva (ASV) with a diameter of $51 \mathrm{~mm}$ and moderate aortic valve regurgitation (figure 1, videos 1 and 2). Cardiac electrocardiography-gated multidetector CT showed protrusion of the aneurysm into the right ventricular outflow tract (figure 2); three-dimensional reconstruction is also shown (figure 3). The patient was referred to surgery and preoperative coronary angiography showed minimal coronary atherosclerosis. Intraoperative transoesophageal echocardiography demonstrated significant aortic regurgitation (figure 4, videos 3 and 4). Surgical correction was achieved with bovine pericardial patch closure to the right sinus of Valsalva aneurysm and bioprosthetic aortic valve replacement.

ASVs are a rare but dangerous problem. The frequency of rupture for right coronary cusp ASVs is estimated to be approximately $60 \%$. Ruptured ASVs can cause symptoms ranging from gradually worsening fatigue and dyspnoea to sudden cardiac death. The standard of care for ASVs is surgical intervention with 5 to 10 -year survival after repair estimated at $82-97 \% .^{1}$ The patient in this case did well postoperatively and was discharged home with plans for cardiovascular rehabilitation.
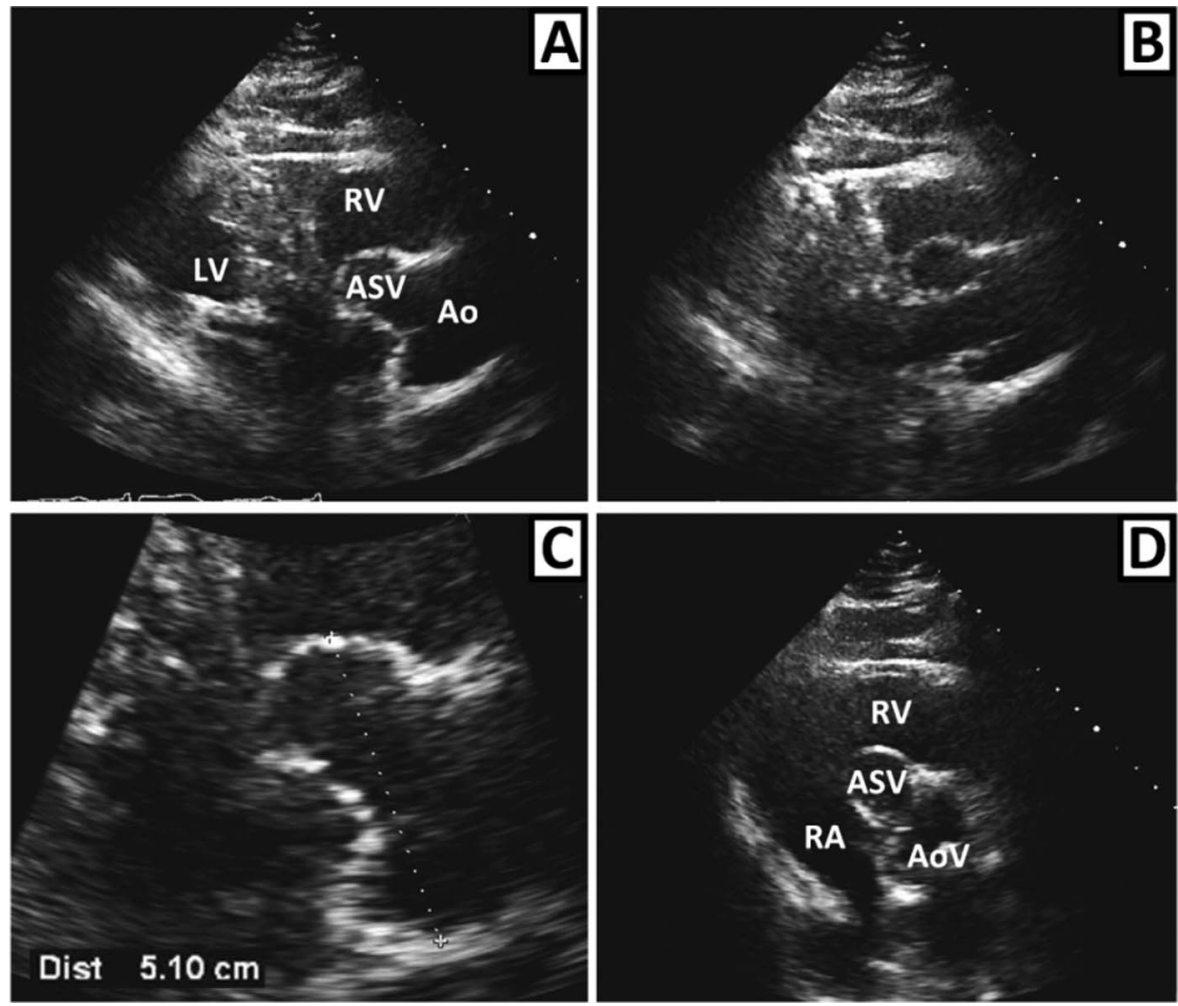

Figure 1 Transthoracic echocardiography. $(\mathrm{A})$ and $(\mathrm{B})$ demonstrate parasternal long-axis views that clearly show the dilated right sinus of Valsalva. (C) A focused view of the sinus of Valsalva aneurysm with the maximal diameter measuring $5.1 \mathrm{~cm}$. (D) Parasternal short-axis view shows the right sinus of Valsalva protruding anterolaterally into the right ventricle. Ao, aorta; AoV, aortic valve; ASV, aneurysm of the sinus of Valsalva; LV, left ventricle; RA, right atrium; RV, right ventricle. 


\section{BMJ Case Reports}
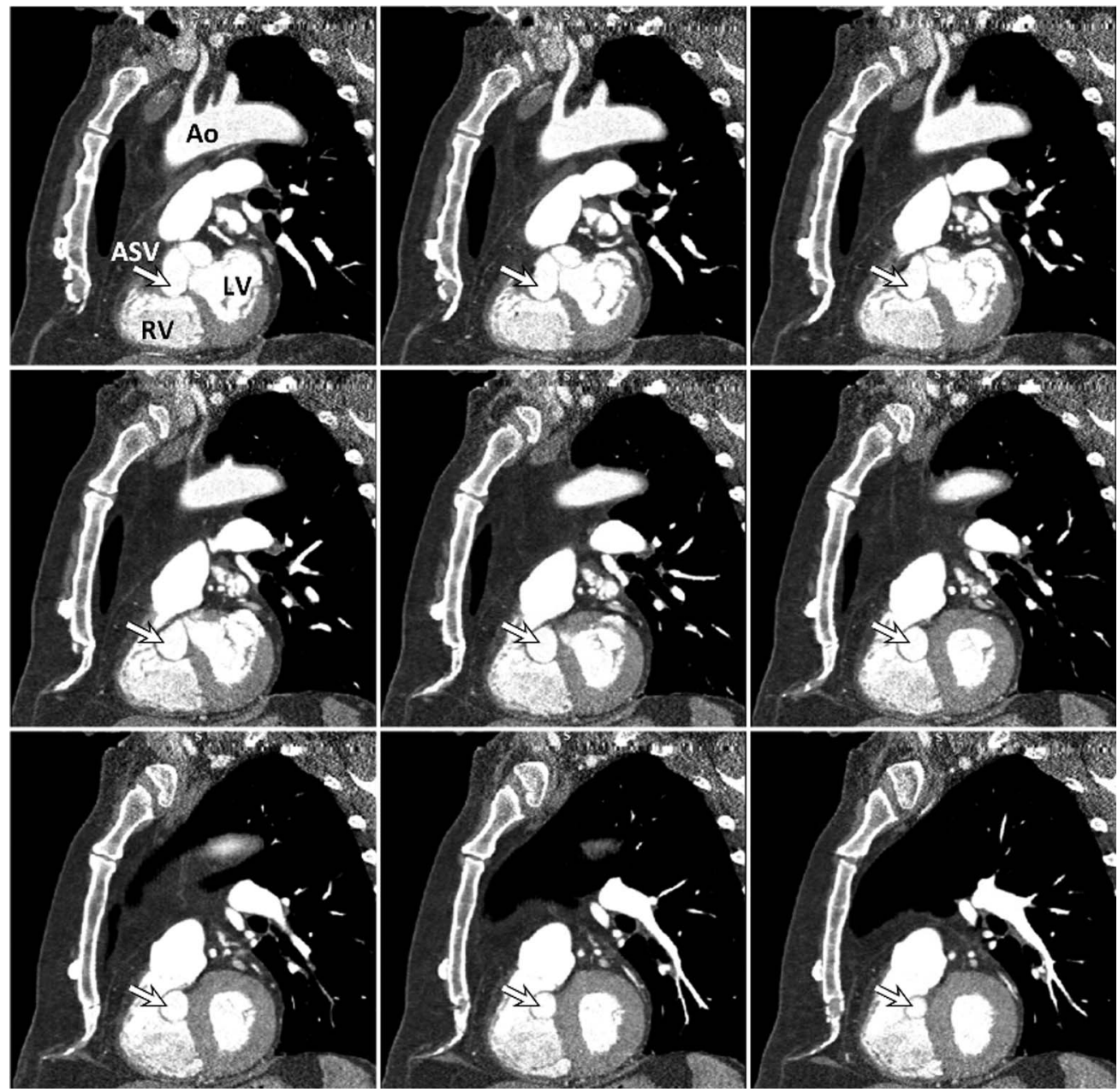

Figure 2 Chest CT angiography. CT angiography oblique sagittal views of the sinus of Valsalva aneurysm. This series of images demonstrates the enlargement of the right sinus of Valsalva (arrow) and subsequent slices reveal the extent of aneurysmal dilatation and protrusion into the right ventricle. Ao, aorta; ASV, aneurysm of the sinus of Valsalva; LV, left ventricle; RV, right ventricle.

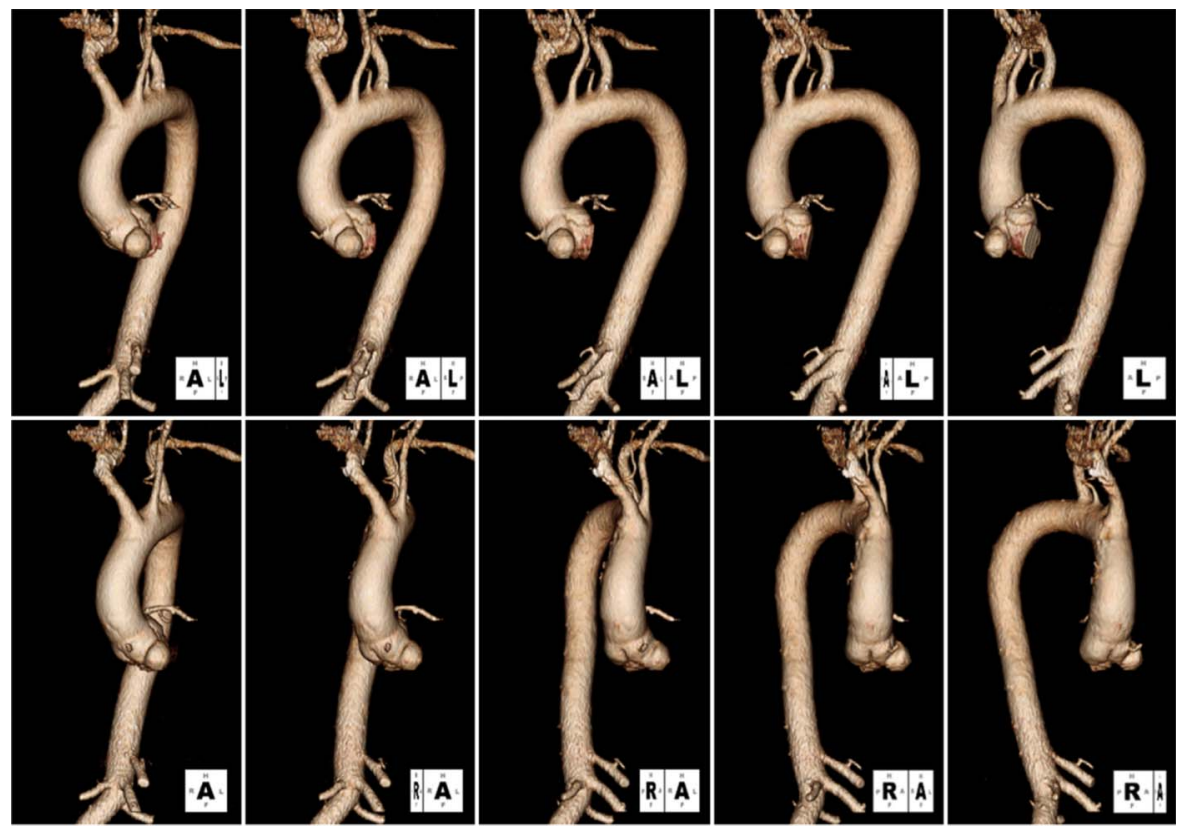

Figure 3 Chest CT angiography with three-dimensional reconstruction. Three-dimensional reconstruction of the CT described earlier enabled high-definition spatial visualisation of the ASV which appeared like a 'bleb' stemming from the root of the aorta. A, anterior; $L$, left; $R$, right. 


\section{BMJ Case Reports}
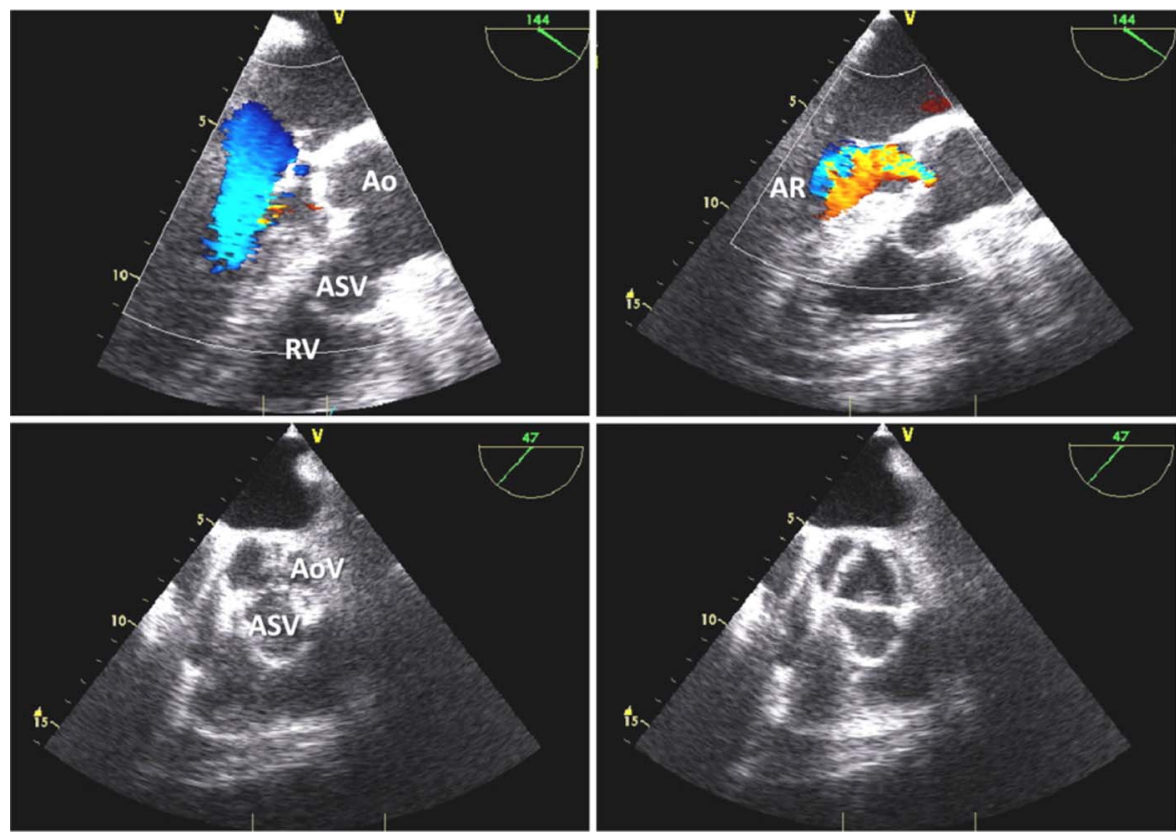

Figure 4 Transoesophageal echocardiography. Intraoperative transoesophageal echocardiography was performed at time of the sinus of ASV repair. The aneurysm is again seen in the above views. A previously noticed moderate aortic valve regurgitation on transthoracic echocardiography was thought to be more significant using this imaging modality. Ao, aorta; AoV, aortic valve; AR, aortic regurgitation jet; ASV, aneurysm of the sinus of Valsalva; RV, right ventricle.

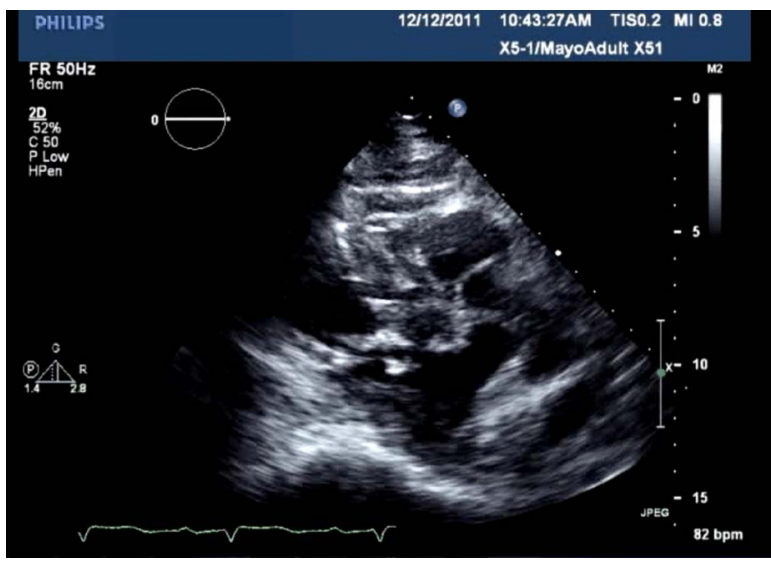

Video 1 Transthoracic echocardiogram clip showing parasternal long-axis views modified to better visualise the right ASV. Ejection fraction was $70 \%$ with no wall motion abnormalities.

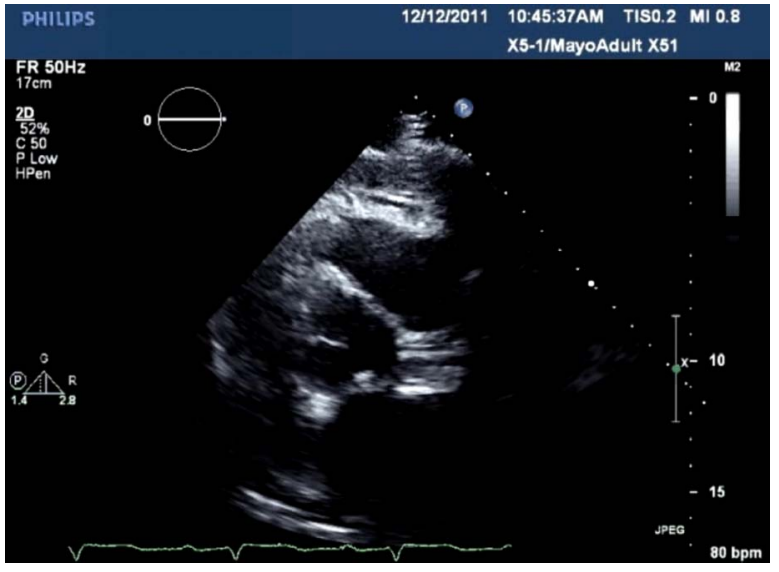

Video 2 Transthoracic echocardiogram clip showing parasternal short-axis views. The aneurysm is clearly visualised in this clip stemming from the right sinus of Valsalva. 


\section{BMJ Case Reports}

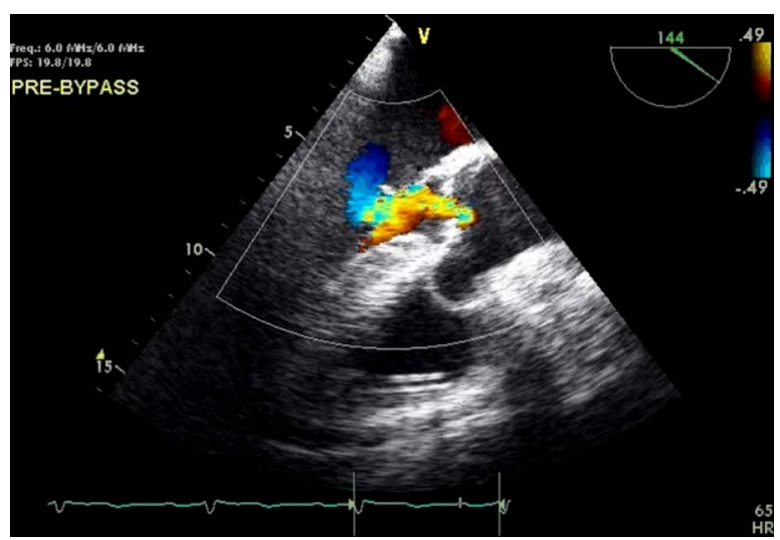

Video 3 Intraoperative transoesophageal echocardiogram views again demonstrating the thin-walled right ASV protruding into the right ventricle. On prior transthoracic echocardiograms, the patient was thought to have moderate aortic regurgitation but on this transoesophageal study, it was thought to be more severe.

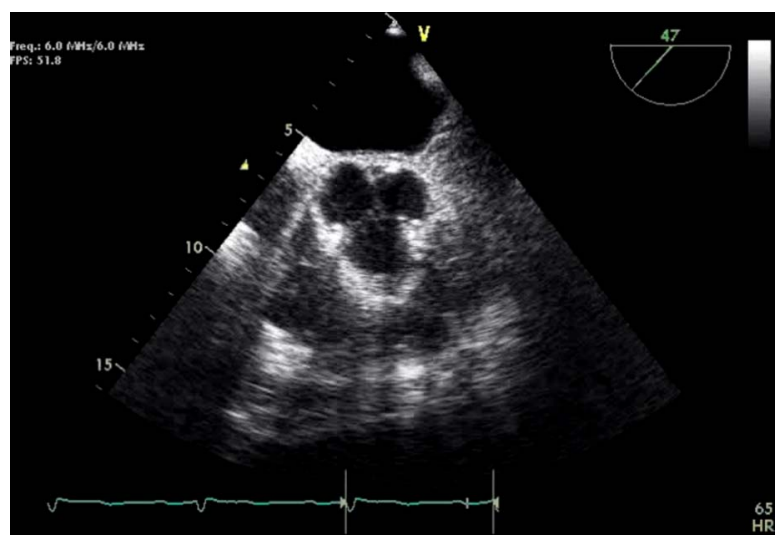

Video 4 Intraoperative transoesophageal echocardiogram views again demonstrating the thin-walled right ASV protruding into the right ventricle. On prior transthoracic echocardiograms, the patient was thought to have moderate aortic regurgitation but on this transoesophageal study, it was thought to be more severe.

\section{Learning points}

- Sinus of Valsalva aneurysms most commonly affect the right coronary cusp and are associated with a high incidence of rupture.

- Rupture of the sinus of Valsalva aneurysm can present with a wide array of symptoms ranging from mild atypical chest pain and exertional dyspnoea to cardiogenic shock and sudden cardiac death.

- Unruptured sinus of Valsalva aneurysms frequently cause aortic valve insufficiency and in the case of right sinus of Valsalva aneurysm, obstruction of the right ventricular outflow tract can also occur with large aneurysms.

- Surgical correction is the therapy of choice and has excellent outcomes.

\section{Competing interests None.}

Patient consent Obtained.

\section{REFERENCE}

1. Ott DA. Aneurysm of the sinus of Valsalva. Semin Thorac Cardiovasc Surg Pediatr Card Surg Annu 2006:165-76.

Copyright 2012 BMJ Publishing Group. All rights reserved. For permission to reuse any of this content visit http://group.bmj.com/group/rights-licensing/permissions.

BMJ Case Report Fellows may re-use this article for personal use and teaching without any further permission.

Please cite this article as follows (you will need to access the article online to obtain the date of publication).

Jouni H, Driver SL, Wright RS, Timimi F. Danger above: a classic case of an unruptured right sinus of Valsalva aneurysm. BMJ Case Reports 2012;10.1136/bcr-2012-007437, Published XXX

Become a Fellow of BMJ Case Reports today and you can:

- Submit as many cases as you like

- Enjoy fast sympathetic peer review and rapid publication of accepted articles

- Access all the published articles

- Re-use any of the published material for personal use and teaching without further permission

For information on Institutional Fellowships contact consortiasales@bmjgroup.com

Visit casereports.bmi.com for more articles like this and to become a Fellow 